\title{
POLÍTICA CRIMINAL DE DROGAS: O PAPEL DA DEFENSORIA PÚBLICA E A SELETIVIDADE PENAL
}

\section{CRIMINAL DRUG POLICY: THE ROLE OF PUBLIC DEFENSE AND CRIMINAL SELECTIVENESS}

\author{
Paulo Thiago Fernandes Dias ${ }^{1}$ \\ Sara Alacoque Guerra Zaghlout ${ }^{2}$
}

\section{RESUMO}

O presente estudo buscou analisar a importância da Defensoria Pública na defesa de pessoas acusadas de tráfico de drogas e o estudo da seletividade penal na atual Política Criminal de Drogas no Brasil. Pois a clientela do sistema penal é normalmente composta por pessoas pertencentes aos mais baixos níveis sociais e são justamente esses os assistidos pela Defensoria Pública, já que elas fazem parte desse processo de criminalização seletivo e desigual de pessoas dentro da população total e são os principais alvos do estereotipo perseguido como traficante de drogas.

Palavras-chave: Seletividade Penal; Política Criminal de Drogas; Defensoria Pública; Criminologia; Sistema Penal.

\begin{abstract}
The present study sought to analyze the importance of the Public Defender's Office in the defense of persons accused of drug trafficking and the study of criminal selectivity in the current Criminal Drug Policy in Brazil. For the clientele of the penal system is usually composed of people belonging to the lowest social levels and these are precisely those assisted by the Public Defender, since they are part of this process of selective and unequal criminalization of people within the total population and are the main targets Of the stereotype pursued as drug trafficker.
\end{abstract}

Keywords: Selectivity; Criminal Drug Policy; Public defense; Criminology; Criminal system.

\footnotetext{
${ }^{1}$ Mestre em Ciências Criminais pela PUCRS, Especialista em Direito Penal e Processual Penal pela UGF, Advogado. Rio Grande do Sul (Brasil). E-mail: paulothiagofernandes@ hotmail.com

${ }^{2}$ Mestranda em Ciências Criminais pela PUCRS. Especializanda em Processo Penal pela Faculdade Anhanguera. Advogada. Rio Grande do Sul (Brasil). E-mail: sah.alacoque@ hotmail.com
} 


\section{INTRODUÇÃO}

Quando é levantado o tema referente à Política Criminal de Drogas muitos são os enfoques que permitem ser abordados. Levando em conta tal amplitude, aqui nos foi oportuno escolher como objeto de estudo a seletividade penal na política criminal de drogas e a importância do papel da Defensoria Pública como meio de minimizar os prejuízos trazidos pela seletividade de pessoas acusadas de tráfico de drogas. Levando como objetivo geral o estudo da seletividade do modelo de política criminal de drogas do Brasil, reflexo do alto encarceramento de pessoas presas por tráfico de drogas.

Partimos da hipótese de que a clientela do sistema penal é normalmente composta por pessoas pertencentes aos mais baixos níveis sociais e são justamente esses os assistidos pela Defensoria Pública, já que elas fazem parte desse processo de criminalização seletivo e desigual de pessoas dentro da população total. E que são justamente essas pessoas que foram estigmatizadas em um perfil para se diferenciar traficante e usuário.

Para tanto, o trabalho será dividido em dois capítulos distintos, que analisarão, mediante pesquisa bibliográfica as questões que, em nosso entender, são de maior relevância na temática abordada, em especial estudos sobre a política criminal de drogas, criminologia e criminologia crítica.

Em um primeiro momento será abordado de modo geral e introdutório a importância da instituição da Defensoria Pública na defesa não só de pessoas pobres, mas também dos grupos vulneráveis, com o papel primeiro de fazer com que justiça chegue a todos de maneira democrática.

Em seguida, é estudada a seletividade penal na política criminal de drogas vigente, a dificuldade em se diferenciar a figura do traficante e do usuário, - o que acabou resultando na criação de um perfil estigmatizante para o traficante de drogas -, e alguns aspectos trazidos pela Nova Lei de Drogas (Lei 11.343/2006), em especial o endurecimento no tratamento para o traficante de drogas e tais consequências.

A abordagem contribuirá para o desenvolvimento da pesquisa científica na área, bem como no campo prático no que tange às políticas efetivas de redução da violência institucional, tendo como finalidade mor a busca pelo respeito aos direitos fundamentais, enquanto valores indissociáveis do Estado Democrático de Direito.

O tema, portanto, demonstra nítida importância, visto que os direitos fundamentais devem ser respeitados por todos de maneira igualitária, independente da sua classe, posição social ou cor do indivíduo. 


\section{DO PAPEL DA DEFENSORIA PÚBLICA COMO "MINIMIZADOR" DA SELETIVIDADE NO SISTEMA PENAL}

A Defensoria Pública foi instituída como ferramenta para a consolidação dos direitos fundamentais, em especifico ao acesso à justiça. Tendo como um dos principais objetivos o de fazer com que a justiça chegue a todos de maneira democrática, (principalmente no Brasil, onde a desigualdade social é cada vez maior).

Assim, ela veio com o encargo de amparar não apenas os pobres, mas também os grupos vulneráveis, em todos os graus de jurisdição, como meio de tentativa para amenizar a discrepância de armas por essa parte da população que já é tão discriminada e perseguida.

A Constituição Federal de 1988, intitulada como "Constituição cidadã", trouxe expressamente em seu artigo 134 que a Defensoria é instituição essencial à função jurisdicional do Estado, incumbindo-lhe a orientação jurídica e a defesa, em todos os graus, dos necessitados.

Na visão de BISSOCHI (2009) o papel da Defensoria vai além do que se está expresso no texto constitucional. A autora acredita que um dos principais motivos para a não concretização dos direitos fundamentais se dá pela insuficiência de recursos. E que o papel da Defensoria seria justamente garantir que tais direitos cheguem a todos, e que dessa forma está a Instituição ligada diretamente à realização da cidadania plena.

\footnotetext{
Na realidade, o papel da Defensoria Pública vai muito além do que se percebe da interpretação literal dos dispositivos constitucionais. A Defensoria Pública é, por vocação constitucional, instituição que se presta a buscar a realização da dignidade da pessoa humana e de grande parte dos demais que lhe são correlatos. É pacífico que o "não exercício" dos direitos fundamentais deve-se, em grande parte, à carência financeira da população brasileira. Fragilidade econômica que leva ao analfabetismo, a condições precárias de saúde, ao subemprego, à violência, à falta de moradia, à marginalidade social e especialmente à total e completa alienação quanto a seus próprios direitos, que culmina, inevitavelmente na ausência de dignidade. [....] Se a hipossuficiência é um dos maiores, se não o maior problema da sociedade brasileira, representando um grande entrave à eficácia social dos direitos fundamentais e a Defensoria Pública foi criada especialmente para garantir integralmente os direitos desta parcela da população, impossível não concluir pela essencialidade desta instituição à realização da cidadania plena. (BISSOCHI, 2009, p.8183)
}

A Lei Orgânica da Defensoria Pública teve recentes alterações trazidas pela Lei Complementar número 132, ao alterar redação do artigo $3^{\circ}$, letra $\mathrm{A}$, incluindo objetivos expressos para a Defensoria Pública, tais como a: primazia da dignidade da pessoa humana e a redução das desigualdades sociais, a afirmação do Estado Democrático de Direito, a prevalência dos direitos humanos, a garantia dos princípios constitucionais da ampla defesa e do contraditório. 
Porém, não bastam tantas garantias expressas (normas programáticas) na Constituição, se a Defensoria Pública não tiver recursos e estrutura para amparar todos àqueles que dela necessitam. Nas palavras de SALVIANO (2010), trata-se de medida indispensável para a Defensoria concretizar tais direitos fundamentais previstos na Carta Maior.

\footnotetext{
Entretanto, muito embora esteja constitucionalmente prevista a assistência jurídica integral aos necessitados, ainda há um longo caminho a ser percorrido, de sorte que nada adianta a Constituição prever diversos direitos e garantias fundamentais aos cidadãos, se não for disponibilizado o acesso à justiça aos carentes de recursos que não têm condições de contratar um advogado. Portanto, o posicionamento que ora defendemos é o de que é indispensável o fortalecimento das Defensorias Públicas, no intuito de melhor estruturá-las, viabilizando, por via reflexa, a concretização dos direitos fundamentais previstos na Carta Magna. (SALVIANO, 2010, p.97)
}

Recentemente, a Defensoria Pública ganhou forças com a aprovação e promulgação da Emenda Constitucional n. 80, de 29 de maio de 2014(PEC das Defensorias ou PEC Defensoria para todos), que trouxe alterações ao artigo 134 e na estrutura do Título IV da Constituição, mais especificamente na Seção III "Da Advocacia e Defensoria Pública”. Passa, então, a Defensoria Pública a ter seção própria, assim como a Advocacia Pública. A PEC também acrescenta o artigo 98 ao Ato das Disposições Constitucionais, estipulando um prazo de 08 (oito) anos para que a União, os Estados e o Distrito Federal se organizem para poder contar com defensores públicos em todas as unidades jurisdicionais, sendo proporcional a demanda jurisdicional e à respectiva população.

O artigo 134 passou a dispor de maneira expressa a Defensoria Pública como instituição permanente, essencial à função jurisdicional do Estado. Incumbindo-lhe, como expressão e instrumento do regime democrático, fundamentalmente, a orientação jurídica, a promoção dos direitos humanos e a defesa em todos os graus, judicial e extrajudicial, dos direitos individuais e coletivos, de forma integral e gratuita, aos necessitados, na forma do inciso LXXIV do artigo $5^{\circ}$ da mesma Carta Magna. Acrescentou, também, o parágrafo $4^{\circ}$ (quarto) - do mesmo mencionado art.134 -, os princípios institucionais da unidade, indivisibilidade e independência funcional, podendo ser aplicado também, o que couber no disposto nos artigos 93 e inciso II do art.96 da mesma Lei Maior.

$\mathrm{Na}$ verdade o constituinte não trouxe nada inédito para ordenamento jurídico, pois a modificação do texto constitucional já existia na Lei Orgânica da Defensoria Pública (artigo $1^{\circ}$ da LC n ${ }^{\circ}$ 80/1994, com redação dada pela Lei Complementar nº 132, de 2009 e artigo $3^{\circ}$ ). Mas deixou de forma clara na Lei Maior, a autonomia da instituição.

A alteração promove ainda mais o papel e a importância da Defensoria Pública com a sua ligação do Estado Democrático de Direito, pois possibilita que a população marginalizada tome 
conhecimento de seus direitos e possam exercê-los, participando diretamente na construção de uma democracia participativa.

ROCHA (2014) fala da importância prática da autonomia da Defensoria Pública na concretização da cidadania. Ele deixa claro que sem recursos financeiros é muito mais fácil o cidadão sofrer prejuízos ou injustiças em processos judiciais.

A autonomia das Defensorias Públicas, constante do parágrafo $2^{\circ}$, do artigo 134 , da CF/88, é das medidas mais salutares para a realização da cidadania em seu sentido amplo. $\mathrm{O}$ cidadão sem recursos financeiros é normalmente o mais penalizado pelo descaso da ação estatal e, com frequência, sofre prejuízos ou mesmo injustiças em processos judiciais por não poder pagar advogados privados. A instituição da Defensoria permite a esse cidadão romper essa barreira, e, com a autonomia, devem aumentar os recursos financeiros disponíveis, logo, o alcance e a força de ação desse órgão. Além disso, fica o mesmo mais protegido de ingerências diretas ou indiretas de agentes de outros órgãos do Estado, em razão da antiga fragilidade de recursos. (ROCHA, 2014, p.26)

SOUZA (2010), em sua dissertação de mestrado fala sobre a importância do papel da defensoria pública no papel de instrumento para realização dos direitos fundamentais, em especial daquela parcela populacional excluída.

Ele acredita que o acesso à justiça passa a ser de fato um dos serviços públicos de assistência jurídica exercido pela Defensoria Pública por causa do grande número de pessoas pobres e marginalizadas. Dessa forma, a Defensoria passaria então, a desempenhar um papel fundamental para a concretização dos direitos fundamentais, em especial aqueles assistidos pelo sistema punitivo, que é claramente estigmatizante e seletivo. ${ }^{3}$

Aponta também, outro motivo para a existência e importância da Defensoria Pública - a violência social e o processo de criminalização - chegando à conclusão que a Defensoria tem um papel de suma importância quando se fala em seletividade penal. Ele acredita que de acordo com a teoria do "Labeling approach" perceberíamos que o sistema penal está longe de ser justo ou igualitário. E que a resposta penal das instituições que as realizam são estruturadas para combater apenas as condutas negativas criminosas. E seria por isso que o sistema penal possui também um caráter simbólico, porque os seus institutos de repressão não dão conta de todas as ações imputadas como criminosas, e por isso, irão dirigir suas atividades de repressão para um determinado grupo estigmatizado de pessoas, aqueles que são selecionados nas camadas mais pobres da população. (SOUZA, 2010)

\footnotetext{
${ }^{3}$ Fabio Luis Mariani, cita Ferrajoli: (2010) apud "El resultado de semejante y creciente desigualdade es el carácter cada vez más classista de la justiça penal em todos los países occidentales: desde Italia hasta la Argentina y Brasil y los otros países latinoamericanos; desde Estado Unidos hasta los demás países europeos. Prueba de ello es la composición social de la problacion carcelaria, formada, si no unicamente, al menos en su mayor parte - tal como muestran las estadísticas judiciales de estos países - por sujetos pobres y marginados; inmigrantes, negros, tóxico-dependientes, detenidos por pequenos contra el patriminio"
} 
Desta forma, far-se-á, de uma importância ímpar na defesa principalmente daqueles que são submetidos ao sistema penal. Sistema esse que como se observará, é muitas vezes seletivo, e que está longe de proteger e punir a todos de maneira igualitária.

\section{DA SELETIVIDADE PENAL NA POLITICA CRIMINAL DE DROGAS}

ANDRADE (2003), fala sobre a clientela penal, que "geralmente é composta por pessoas pertencentes a níveis sociais mais baixos", e segundo a autora, isso é resultado de um sistema seletivo e desigual:

\footnotetext{
A clientela do sistema penal é composta, 'regularmente', em todos os lugares do mundo, por pessoas pertencentes aos mais baixos estratos sociais" e, conclui, que isso "é resultado de um processo de criminalização altamente e seletivo e desigual de 'pessoas' dentro da população total, às quais se qualifica como criminosos. (ANDRADE, 2003, p.52)
}

BARATTA (2013), em sua obra, critica alguns mitos, e fala sobre a seletividade no direito penal. O mito de que a lei penal é igual para todos, que todos os autores de comportamentos antissociais e violadores de normas penalmente sancionadas têm iguais chances de torna-se sujeitos, e com as mesmas consequências do processo de criminalização. BARATTA (2003), sabiamente, deixa sua crítica sobre tal mito. Para o autor a lei penal não é igual para todos, que o status de criminoso é distribuído de modo desigual entre os indivíduos. E diz mais:

\footnotetext{
A crítica se dirige, portanto, ao mito do direito penal como o direito igual por excelência. Ela mostra que o direito penal menos desigual que os outros ramos do direito burguês, e que, contrariamente a toda aparência, é o direito desigual por excelência (BARATTA, 2013, p.162)
}

As primeiras leis que vieram criminalizar o uso e venda de drogas surgiram quando as substâncias que, até então, eram utilizadas por grupos dominantes da sociedade passaram a ser consumidas por grupos minoritários.

Nos Estados Unidos, por exemplo, a proibição do ópio, da cocaína e da maconha aconteceu quando pessoas que não eram da alta sociedade começaram a fazer uso das substâncias. Enquanto os consumidores de ópio eram senhoras brancas de meia-idade era considerado normal o uso do produto da papoula, não oferecendo qualquer risco à sociedade; entretanto, a partir do momento em que imigrantes chineses se tornaram consumidores surgiu a preocupação dos "estragos" que esses poderiam causar a sociedade, principalmente para as classes média e alta, como se o uso da substância acordasse uma predisposição natural ao crime, inerente ao caráter daqueles imigrantes. 
O mesmo entendimento ocorreu nos processos de criminalização da cocaína e da maconha em relação às minorias envolvidas em cada caso

Antes da entrada em vigor da Lei 11.343/2006, era comum que a distinção entre usuário e traficante se desse nos artigos da legislação anterior - Lei nº 6.368/76. Eram os próprios artigos que representavam socialmente e distinguiam essas duas figuras. A atual legislação trouxe algumas novidades, sendo uma delas deslocar o usuário para o sistema de saúde (acabando com a pena de prisão) e aumentar a pena mínima para o traficante ${ }^{4}$.

Ou seja, nos termos da atual legislação, o usuário é visto como um "doente", objeto das instituições de saúde e assistência social; e o traficante ainda é tratado como perigoso, o mal, o inimigo ${ }^{5}$ da sociedade.

Hoje, a atual política criminal de drogas ainda sofre reflexos do seu passado atormentado de preconceitos e discriminações. A superlotação dos presídios é a constatação de tal ato discriminatório. A atual Lei de Drogas (11.343/2006) é responsável pela maior parte de pessoas encarceradas $^{6}$. Os principais alvos são as pessoas pobres e negras, resultantes de um estereotipo já consolidado ${ }^{7}$.

ZAFFARONI e PIERANGELI (2008) ao tratarem do tema, afirmam que o sistema penal seleciona pessoas ou ações, criminaliza certas pessoas segundo sua classe e posição social. Que o sistema penal costuma se orientar por estereótipos, criados a partir de características dos setores marginalizados e humildes.

\footnotetext{
${ }^{4}$ Sabe-se que o aumento de pena para combater a criminalidade é uma ideia fracassada. Ao mesmo tempo que a prisão não é meio de contenção de violência ou de criminalização, muito pelo contrário. Prisão gera reincidência, que gera violência. Foucault em Vigiar e Punir quando ressaltava sobre a prisão e sua criação, já falava das mesmas críticas que vemos hoje. Que ela não diminuía a taxa de criminalidade, fabricava delinquentes (sobretudo por não trata-los como seres humanos), aumentava a corrupção, dentre outras coisas. Afinal, a prisão ao tentar corrigir não obtém sucesso. Sútil é a ilusão de que as leis são criadas como forma de justiça e não em ignorância e preconceito. Nesse contexto, lembramos também do duplo objetivo da prisão, muito bem exposto por Michel Foucault também em Vigiar e Punir. Ele afirma que embora a prisão tenha sido institucionalizada para garantir a recuperação do criminoso por meio do isolamento, o objetivo real era manter essa massa de excluídos sob constante vigilância e repressão, de forma a segregá-los da sociedade. Afinal, a lei penal é feita por uma classe para ser aplicada à outra.

${ }^{5} \mathrm{O}$ "inimigo" é aquele que assume o perfil do estranho à comunidade, a quem, por sua apontada "periculosidade", não são reconhecidos os mesmos direitos dos pertencentes à comunidade e que, assim, desprovido de dignidade e de direitos, perde sua qualidade de pessoa, tornando-se uma "não-pessoa" (ZAFFARONI 2006).

${ }^{6}$ Em entrevista no dia 09/09/2015, no Seu Jornal da TVT, a assessora especial de Políticas sobre Drogas da Secretaria de Direitos Humanos da prefeitura de São Paulo, Maria Angélica Comis, afirmou que o encarceramento aumentou 325\% de 2006 a 2015.

${ }^{7}$ Segundo o "Mapa do Encarceramento: os Jovens do Brasil", divulgado pela Secretaria-Geral da Presidência da República, feito pela pesquisadora Jacqueline Sinhoretto com base nos dados do Sistema Integrado de Informações Penitenciárias (InfoPen) do Ministério da Justiça, os crimes contra o patrimônio e relacionados às drogas são os mais comuns, segundo o estudo. Somados, atingem cerca de $70 \%$ das causas de prisões, e o crescimento teria sido impulsionado pela prisão de jovens, negros e mulheres.
} 
Tudo isto demonstra que, ao menos em boa medida, o sistema penal seleciona pessoas ou ações, como também criminaliza certas pessoas segundo sua classe e posição social. Assim, está visto que não limita muito as possibilidades laborais de certos profissionais condenados, mas limita as de outras pessoas. Há uma clara demonstração de que não somos todos igualmente "vulneráveis" ao sistema penal, que costuma orientar-se por "estereótipos" que recolhem os caracteres dos setores marginalizados e humildes, que a criminalização gera fenômeno de rejeição do etiquetado como também daquele que se solidariza ou contata com ele, de forma que a segregação se mantém na sociedade livre. A posterior perseguição por parte das autoridades com rol de suspeitos permanentes, incrementa a estigmação social do criminalizado (ZAFFARONI; PIERANGELI, 2008, p.36)

BIANCHINI (2000), em poucas palavras, resume, ao dizer que o sistema penal, seleciona pessoas e não ações como também criminalizam a pessoas determinadas, segundo a sua classe a posição social.

BARATTA (2013), quando fala sobre a seletividade do direito penal, ele as divide em seletividade primária, que seria na produção das normas, e em seletividade secundaria, que se trata dos mecanismos de aplicação das normas (o processo penal).

Assim, acreditamos que a Lei 11.343/2006 não é apenas seletiva em sua aplicação, mas foi seletiva também na sua elaboração normativa (seletividade primária). Segundo a Lei de Drogas, configurariam crimes as condutas de adquirir, guardar, ter em depósito, transportar ou trazer consigo. Porém, tais condutas estão previstas tanto nos tipos penais do artigo 28 (consumo pessoal) e artigo 33 (tráfico de drogas), o critério de diferenciação de uma para outra, se daria de modo altamente subjetivo, que é justamente onde apontamos como caracterizador da seletividade.

A partir do momento em que o legislador considerou como critérios de diferenciação o local e às condições em que se desenvolveu a ação, às circunstâncias pessoais e sociais do agente como forma de distinguir traficante e usuário, ele ao mesmo tempo criou critérios subjetivos e discriminatórios. Dando margem à inúmeras interpretações subjetivas e distintas por quem as aplica.

Sobre a legislação não especificar a quantidade de droga para a diferenciação de usuário para traficante, OLINGER (2015), em sua obra fala que deixar apenas para o juiz analisar as circunstancias e o perfil do agente faz com que tal seletividade seja ainda mais evidente, e diz mais:

Dessa forma existe uma tendência a continuar prendendo negros e pobres como traficantes, já que mesmo que sejam encontrados com uma quantidade muito pequena de droga, tem grande probabilidade de ser acusados, pelas circunstancias e perfil social, de estar servindo de atravessador/avião, enquanto o menino de classe média vai ter um bom advogado e mostrar que, com seu perfil e condição social não é traficante. (OLINGER, 2015 p.12)

Desta forma é fácil criar estereótipos para diferenciar um ou outro, ficando muito mais fácil prejudicar as classes mais vulneráveis. É só pensar nas duas figuras distintas: o menino negro, morador da favela, e o menino branco, em seu carro importado. 
O traficante estigmatizado, ou seja, aquele que apresenta uma relação entre o atributo na venda da substancia entorpecente e o estereotipo do criminoso (preto, pobre, favelado) é um verdadeiro passe livre para as ações genocidas (D’ELIA, 2014). Já temos, assim, ilustrados a figuras de quem é o traficante e usuário. Afinal, meninos pobres e negros, vendem drogas para meninos ricos, não é mesmo? ${ }^{8}$

Essa seletividade de pessoas e classes é constatada desde o momento da investigação preliminar (em geral, resumida ao flagrante) pelos policiais até a decisão judicial, pois, como explica ZALUAR (2004), quem produz as provas e monta o processo são os policias, fruto de nossas tradições inquisitórias. Em resumo, são os policiais que decidiram quem será processado por tráfico ou apenas pelo uso.

Em entrevista publicada na Revista "Caros Amigos", Nilo Batista e Vera Malaguti Batista tecem críticas sobre o assunto, de quem seria o traficante e o usuário:

\begin{abstract}
Nilo Batista - O menino branco que tenha 400 gramas de maconha, que tenha situação econômica...

Vera Malaguti Batista - Aí eles dizem que ele comprou porque vai fumar a longo prazo. Isso é um dado concreto! O outro está com uma pequena quantidade, mas como é pobre, mora em favela e como ele está com quatro papelotes ele não vai comprar, ele vai vender. Ele é ontologicamente traficante. Ele é criminalizável. E ao longo da história... é droga agora, antes era a capoeira, e antes da capoeira...

Nilo Batista - A gente vive a ilusão de que o sistema penal opera a partir do que o cara fez. Dogma, se você não acreditar nisso... E na verdade não é. O que você fez participa, mas o que você é determina se você vai ser selecionado ou não. Verinha e eu num carro poderíamos ter seis quilos de maconha no banco de trás. A polícia não vai nos parar. Dois garotos negros, num carro sambado... e se o carro novo, aí mesmo é que dançam! ${ }^{9}$
\end{abstract}

D'ELIA (2014) relata um caso em especifico que ocorreu com um dos seus colegas de concurso para delegado. Esse delegado, atuou, em flagrante, dois jovens residentes da zona sul pela conduta descrita para o usuário, porte de drogas para consumo próprio, por estarem transportando, em um veículo importado, 280 gramas de maconha. O delegado teria se com vencido que a quantidade não era determinante para prendê-los por tráfico, já que a forma como a droga estava guardada - em dois volumes prensado -, bem como o fato de os rapazes serem estudantes universitários e terem empregos fixos, além da folha de antecedentes criminais limpa, era indicio de

\footnotetext{
${ }^{8}$ Orlando Zaccone D’Elia comenta sobre esse "tal traficante estigmatizado": “aquele que apresenta uma relação entre o atributo na venda da substância entorpecente e o estereotipo do criminoso (preto, pobre, favelado) é um verdadeiro passe livre para as ações genocidas [...] O estereotipo do bandido vai-se consumando na figura de um jovem negro, funkeiro, morador da favela, próximo do tráfico de drogas, vestido com tênis, boné, cordões, portador de algum orgulho ou de poder e de nenhum sinal de resignação ao desolar cenário da miséria e fome que o circunda (D’ELIA, 2014)”.

${ }^{9}$ Recomendamos a leitura da entrevista completa: Todo Crime é Político. Revista Caros Amigos. São Paulo. Disponível em: $\quad<$ http://webcache.googleusercontent.com/search?q=cache:fnUdUgoqqh4J:www.pdtrj.org.br/docs/Entrevista\%2520de\%2520Nilo\%2520Batista\%2520para\%2520a\%2520Revista\%2520Caro\%2520Amig os.doc $+\& \mathrm{~cd}=2 \& \mathrm{hl}=\mathrm{pt}-\mathrm{BR} \& \mathrm{ct}=\mathrm{clnk} \& \mathrm{gl}=\mathrm{br}>$
} 
que segundo o depoimento deles, a droga era para consumo pessoal. O delegado, então, lavrou o flagrante e, autorizou a concessão da fiança e a liberdade provisória dos delitos (conforme a lei em vigor naquele tempo).

Ainda hoje, o autor se pergunta se a conduta desse seu companheiro de profissão seria e mesma se os jovens fossem negros e estivessem transportando drogas para uso próprio em um ônibus, ainda que comprovassem trabalho e tivessem a ficha sem anotação.

A partir dessas tantas questão já expostas, CARVALHO (2015), acredita poder levantar algumas hipóteses referentes a "violência institucional e seletiva que o Brasil vive nas últimas décadas:

(Primeira) O Brasil, longe de ser o país da impunidade, encarcera muito, ou seja, o sistema punitivo opera de forma contrária ao que é cotidianamente divulgado, sobretudo pela imprensa. Mas ao mesmo tempo que encarcera muito, encarcera muito mal, no sentido de que inúmeras condutas não lesivas (crimes sem violência ou grave ameaça) não demandariam o uso da prisão. A propósito, conforme as lições da crítica criminológica, o cárcere é o instrumento mais caro disponibilizado pelo Estado para tornas as pessoas piores. (Segunda) O Poder Legislativo, que opera na criminalização primária, não é o único responsável pelos altos índices de prisionalização. O Poder Judiciário, nas últimas décadas, tem abdicado de ser um filtro constitucional à demanda criminalizadora e, em vários momentos, tem aderido ao populismo punitivo. Neste e, em vários momentos, tem aderido ao populismo punitivo. Neste sentido, seria fundamental uma política institucional de afirmação da Constituição contra as tendências de "decisionismo populista"

(Terceira) A Polícia, historicamente cúmplice das políticas escravagistas, durante o período da Ditadura Civil-Militar densificou as funções de seletividade racial, ampliando a violência institucional refletida nas práticas de extermínio da juventude negra. Em paralelo, as demais agências do sistema punitivo (Ministério Público e Poder Judiciário) efetivam a seletividade operada pelas Policias e colocam em marcha processos de criminalização e de encarceramento fundado em uma lógica nitidamente racista.

(Quarta) A seletividade racial é uma constância na historiografia dos sistemas punitivos e, em alguns casos, pode ser ofuscada pela incidência de variáveis anônimas. No entanto, no Brasil, a população negra, notadamente aquela que vive na periferia dos grandes centros urbanos, tem sido a vítima preferencial dos assassinatos encobertos pelos "autos de resistência" e do encarceramento massivo, o que parece indicar que o racismo se infiltra como uma espécie de metarregra interpretativa da seletividade, situação que permite afirmar o racismo estrutural, não meramente conjuntural, do sistema punitivo. (CARVALHO, 2015, p.648-649)

Mesmo o legislador querendo trazer critérios objetivos para a caracterização do usuário de drogas, a atual legislação passou longe de objetividade, trazendo uma margem de subjetividade enorme para quem os aplica, sendo muito fácil encaixar pessoas pobres e negras em bairros carentes como traficantes e pessoas brancas de classe média/alta, em bairros de classe médio/alta como usuários, mesmo que a quantidade seja igual ou superior ao segundo caso.

Antes da nova Lei de Drogas (11.343/2006), a pena mínima para o tráfico era de 3 (três) anos, e agora passou a ser de 5 (cinco) anos. A Constituição Federal passou a considera-lo como inafiançável e insuscetível de graça ou anistia. 
O endurecimento no tratamento foi fruto da insegurança e clamor público. A declaração de "guerra contra as drogas"10 nada mais é do que, um sentimento de insegurança pela população. Já que muito foi propagada a ligação direta entre drogas e violência. Não se pode negar que o tráfico é uma das principais causas de violência nos dias atuais, seja por conflitos internos (brigas por território de venda entre traficantes ou por força policial e etc) ou também por conflitos externos (dependentes químicos cometendo crimes para sustentar o vício das drogas, brigas familiares, briga de traficante e usuário, etc). Esse clamor por punição, GAUER (2009) chama de "compulsão pela ordem", que se faz presente nas sociedades, mesmo sendo os regimes democráticos ou totalitários.

Tentou-se amenizar os estragos do tráfico com mais repressão, com penas mais duras e cortando todos os privilégios possíveis ${ }^{11}$, (além de penas privativas de liberdade, é proibido até a concessão de alguns benefícios concedidos pela Lei 8.072/90 - Lei dos Crimes Hediondos -, como o a possibilidade de sursis e penas restritivas de direito ${ }^{12}$. Sobre isso, KARAM (2006), tece alguns comentários:

Uma lei que repete violações a princípios e normas constantes das declarações universais de direitos e das Constituições democráticas jamais poderá ser considerada um avanço. Nenhuma lei que assim suprime direitos fundamentais pode merecer aplausos ou ser tolerada como resultado de uma conformista "política do possível". (KARAM, 2006, p.7)

O problema da segurança pública no Brasil é tratado pela grande maioria das pessoas de forma bastante superficial e homogênea, da forma que os ditos "criminosos" devem ser tratados de forma árdua e repressiva. AZEVEDO (2008) explica:

\footnotetext{
"Nesse contexto, os problemas de segurança apresentados são reduzidos aos desejos de exacerbação e ampliação dos meios de combate ao crime. Equivocadamente a repressão torna-se a única saída vislumbrada pelo coro da opinião pública, produzida e amplificada pela mídia de massas. Criminalidade e combate ao crime são tradicionalmente temas
}

\footnotetext{
${ }^{10}$ Nesse sentido, Maria Lucia Karam (2013) esclarece o verdadeiro propósito da chamada "guerra às drogas". Ela não é e nunca será uma guerra contra as drogas, mas sim contra pessoas. E não quaisquer pessoas, mas sim aquelas pessoas, como sempre, de classe baixa e mais vulneráveis perante a sociedade. Essa classe mostra-se sempre como o alvo principal.

11 Tendo em vista esse panorama criminológico, é fácil visualizar a figura da teoria criada por Jakobs: o direito penal do inimigo. Os Estados Unidos, e outros países, elegeram como inimigos aqueles ditos-cujos que possuíam algum contato com as drogas, fosse como usuário ou como traficante. Esse envolvimento tornou-se mais importante do que a própria condição de ser humano. Para Jakobs, deve-se fazer a distinção de dois tipos de Direito Penal. Primeiro o é o cidadão, a pessoa, um sistema, no qual a pena tem a função de proteger a vigência da norma; de outra banda, há de haver um direito penal dirigido aos inimigos, desviantes por natureza, um sistema no qual a pena tem a função de eliminar um perigo concreto, iminente ou meramente passível de acontecer.

${ }^{12}$ É importante lembrar que a partir do momento em que se equiparou o tráfico de drogas à crime hediondo, a legislação foi contaminada pelo direito penal do inimigo, pois aqueles que forem enquadrados como traficantes, passaram automaticamente a ter um tratamento diferenciado, com restrições de garantias penais e processuais; passaram a ser o inimigo para o direito penal.
} 
políticos conservadores e se adequam privilegiadamente a estratégias populistas." (AZEVEDO, 2008, p.286)

Desta forma, fica evidenciado, que a ideia do endurecimento de penas para diminuir o tráfico é fadada ao fracasso e os maiores prejudicados serão sempre as classes mais vulneráveis. Seja por já terem um estereotipo erroneamente formado, seja por não possuírem recursos econômicos para pagar um advogado. Sem contar que usar o sistema carcerário brasileiro não é meio de contenção de violência. E que ao contrário do que muitos pensam, o Brasil passa longe de ser um país da impunidade, bem pelo contrário, ele prende muito, mas prende muito mal.

Conforme AZEVEDO (2010) novamente nos ensina, ao falar sobre o sistema carcerário brasileiro ser meio de contenção da criminalidade:

\footnotetext{
"O sistema carcerário brasileiro está longe de ser um meio de contenção da criminalidade, tornando-se, ao contrário, cada vez mais um dos maiores propulsores do aumento da violência. Muito distante do propósito de reinserir socialmente, as prisões têm contribuído para o aumento das taxas de criminalidade. $\mathrm{O}$ encarceramento produz reincidência: depois de sair da prisão, aumentam as chances de voltar para ela (delinquência secundária)" (AZEVEDO, 2015, p.100)
}

Dessa forma, já nos é permitido dizer que o direito penal não é igualitário, que prioriza as classes dominantes, e recrimina de forma seletiva as classes mais vulneráveis. Desde que o legislador imputou às drogas um caráter incriminador, criou-se junto, um estereotipo de quem seria julgado usuário (o branco de classe média) e traficante (o negro, pobre, morador de periferia).

\section{CONCLUSÃO}

Diante do exposto, restou claro que a política criminal de drogas é seletiva, e que está longe de respeitar de forma clara o princípio da isonomia. E que lidar com a seletividade penal ainda é um grande desafio hoje, pois, trata-se de um instituto que está enraizado na sociedade.

O trabalho exposto não buscou inovar o assunto referente à seletividade na política crimina de drogas, apenas reforçar a importância em se pensar em novas políticas públicas juntamente com o fortalecimento do instituto da Defensoria Pública.

Foi visto o essencial papel da Defensoria Púbica como tentativa de minimizar essa seletividade e a sua busca por levar justiça à todos. E é justamente por ter esse papel essencial como concretizador dos direitos e das liberdades, que a Defensoria não pode e não deve ser tratada de como inconsequente pelo Poder Público, pois a proteção das pessoas que sofrem inaceitável 
processo de exclusão jurídica e social depende dela. Os direitos não irão valer de nada se os fundamentos que em eles se apoiam sejam desrespeitados pelo Poder Público.

Posteriormente, foi observado que para ser enquadrado como traficante (imputado à pena mais gravosa, comparada a de um crime hediondo) já se criou um estereótipo, resultado de um Direito Penal que não trata de forma igual os desiguais. Dessa forma, além de perseguir os mais pobres e vulneráveis, o sistema penal estará sujeito ao fracasso, pois tal perseguição só irá aumentar a revolta e o sentimento de injustiça entre os menos favorecidos. E os grandes responsáveis pelo tráfico serão esquecidos, já que a perseguição estará voltada para os grupos vulneráveis, via de regra, "usuários" e pequenos traficantes

Dessa forma, há muito o que se pensar e muito o que se discutir. Juntamente com políticas públicas, urge a necessidade de se refazer as percepções sobre as questões das drogas, afastando-se as visões simplificadas baseadas em estereótipos e estigmas.

\section{REFERÊNCIAS}

ADORNO, Sergio. Discriminação Racial e Justiça Criminal em São Paulo. Novos Estudos, n.43, novembro 1995.

Racismo, criminalidade violenta e justiça penal: réus brancos e negros em perspectiva comparativa. Estudos Históricos, Rio de Janeiro, n.18, 1996.

ANDRADE, Vera Regina. Sistema penal máximo x cidadania mínima: códigos da violência na era da globalização. Porto Alegre: Livraria do Advogado, 2003.

AZEVEDO, Rodrigo Ghiringhelli. Segurança pública e direitos fundamentais. Porto Alegre, 2008.

Rodrigo Ghiringhelli. Descarcerização e segurança pública. Revista Carta Capital. Disponível em: www.cartacapital.com.br/sociedade/descarcerizacao-e-segurancapublica. Acesso em: 07 set. 2016.

BACILA, Carlos Roberto. Estigmas: um estudo sobre preconceitos. Rio de Janeiro: Editora Lumen Juris. 2005

BARATTA, Alessandro. Criminologia crítica e crítica do direito penal: introdução à sociologia do direito penal. Rio de Janeiro: Revan, 2013

BATISTA, Nilo. Política criminal com derramamento de sangue. Discursos Sediciosos. Rio de Janeiro. Instituto Carioca de Criminologia (05/06), 1998 
BATISTA, Vera Malaguti. Difíceis ganhos fáceis - drogas e juventude pobre no Rio de Janeiro. Rio de Janeiro: Revan, 2003

. Entrevista: Todo Crime é Político. Revista Caros Amigos. São Paulo. Ano VII, número 77, Agosto 2003, p 29.

BERGERON, Henri. Sociologia da droga. Aparecida: Ideias \& Letras, 2012.

BIANCHINI. Alice. A seletividade do controle penal. Boletim IBCCRIM. São Paulo, n. 30, p. 5164, abril-junho. 2000.

BISSOCHI, Barbara Silveira. A Defensoria Pública como Instrumento Essencial à Cidadania Substancial. In.: VIII Congresso Nacional dos Defensores Públicos. Livro de teses e práticas exitosas: passaporte essencial à cidadania. Porto Alegre, 2009, p. 81-83

BOITEAUX, Luciana. A nova lei anti drogas e o aumento da pena do delito de tráfico de entorpecentes. Boletim IBCCRIM. São Paulo, v.14, n. 167, p. 8-9, out. 2006.

BRASIL, Constituição da República Federativa do Brasil de 1988, Brasília 2 de out. de 1988. Disponível em:〈http://www.planalto.gov.br/ccivil_03/constituicao/ConstituicaoCompilado.htm〉. Acesso em: 10 set. 2016

, Lei n ${ }^{\circ}$ 11.343, DE 23 de Agostod e 2006.Institui o Sistema Nacional de Políticas Públicas sobre Drogas - Sisnad; prescreve medidas para prevenção do uso indevido, atenção e reinserção social de usuários e dependentes de drogas; estabelece normas para repressão à produção não autorizada e ao tráfico ilícito de drogas; define crimes e dá outras providências. Disponivel em: < http://www.planalto.gov.br/ccivil_03/_ato2004-2006/2006/lei/111343.htm>. Acesso em: 10 de set. 2018

Lei Complementar n. 132 de 07 de out. de 2009. Altera dispositivos da Lei Complementar $\mathrm{n}^{\circ}$ 80, de 12 de janeiro de 1994, que organiza a Defensoria Pública da União, do Distrito Federal e dos Territórios e prescreve normas gerais para sua organização nos Estados, e da Lei n ${ }^{\circ} 1.060$, de 5 de fevereiro de 1950, e dá outras providências. Disponível em :< http://www.planalto.gov.br/ccivil_03/leis/lcp/Lcp132.htm >. Acesso em: 10 set. 2016.

. Lei Complementar n. 80 de 12 de jan. de 1994. Organiza a Defensoria Pública da União, do Distrito Federal e dos Territórios e prescreve normas gerais para sua organização nos Estados, e dá outras providências. Disponível em: < http://www.planalto.gov.br/ccivil_03/leis/lcp/Lcp80.htm >. Acesso em: 10 set. 2016.

CALLEGARI, André Luís; ANDRADE, Roberta Lofrano. Traços do direito penal do inimigo na fixação da pena-base. Boletim IBCCRIM, São Paulo, ano 15, n. 178, set. 2007.

CAMPOS, Marcelo da Silveira. Pela metade: as principais implicações da nova lei de drogas no sistema de justiça criminal em São Paulo. São Paulo, 2015. 
Marcelo da Silveira. Seletividade da atuação policial na aplicação da Lei de drogas. Entrevista para a revista Fórum. Disponível em: http://revistaforum.com.br/blog/2013/10/sociologocritica-seletividade-da-atuacao-policialna-aplicacao-da-lei-drogas/. Acesso em: 10 de junho 2016.

CARVALHO. Salo de. A política criminal de drogas no Brasil (estudo Criminológico e Dogmático). RJ: Lumen Juris, 2010.

DEL OMO, Rosa. A face oculta da droga. Rio de Janeiro: Revan, 1990.

D’Elia Filho, Orlando Zaccone. Indignos de vida: a forma jurídica da política de extermínio de inimigos na cidade do Rio de Janeiro. $1^{\circ}$ edição. Rio de Janeiro: Revan, 2015

- Acionistas do nada: quem são os traficantes de droga. Rio de Janeiro: Revan, 2007, $3^{\circ}$ edição, agosto de 2011. $1^{\circ}$ reimpressão, outubro de 2014.

O Debate sobre as Relações Raciais e seus Reflexos no Ordenamento Jurídico Brasileiro. Universitas. Jus (UNICEUB), v. 1, p. 110-145, 2004.

DUARTE, E. C. P.; MURARO, M. ; LACERDA, M. ; DEUS GARCIA, Rafael de. . Quem é o suspeito do crime de tráfico de droga? Anotações sobre a dinâmica dos preconceitos raciais e sociais na definição das condutas de usuário e traficantes pelos Policiais Militares nas Cidades de Brasília, Curitiba e Salvador.. In: Isabel Seixas de Figueiredo; Gustavo Camilo Baptista e Cristiane do Socorro Loureiro Lima. (Org.). Pensando a Seguranca Pública e Direitos Humanos: Temas Transversais. 1ed.Brasília: Ministério da Justiça (SENASP), 2014, v. 5, p. 81-120.

ELBERT, Carlos Alberto. Novo Manual de Criminologia. Tradução Ney Fayet Júnior. Livraria do Advogado, Porto Alegre, 2009.

, Carlos Alberto. Criminologia, Ciência e Mudança Social. Nuria Fabris Editora, São Paulo, 2012.

FOUCAULT, Michel. Vigiar e punir: nascimento da prisão. 35.ed. Petrópolis, RJ: Vozes, 2008

GAUER, Ruth M. Chittó. A sedução da liberdade frente à obsessão pela segurança. Revista Brasileira de Ciências Criminais, $n^{\circ} 76$, São Paulo: Revista dos Tribunais.

HELPES, Sintia Soares. Vidas em Jogo. IBCCRIM, São Paulo, 2014

KARAM Maria Lucia. A Lei $n^{o} 11.343 / 06$ e os repetidos danos do proibicionismo. Boletim IBCCRIM. São Paulo, v.14, n.167, Outubro de 2006

. PROIBIÇÃO ÀS DROGAS E VIOLAÇÃO A DIREITOS FUNDAMENTAIS. Disponível em: $<$ http://www.leapbrasil.com.br/media/uploads/texto/72_Proibi\%C3\%A7\%C3\%A3o\%20\%C3\%A0 s\%20drogas\%20e\%20viola\%C3\%A7\%C3\%A3o\%20a\%20direitos\%20fundamentais\%20\%20Piau\%C3\%AD.pdf?1376532185>. Acesso em: 3 de junho 2016.

"Guerra as drogas" e a criminalização da pobreza. In: Zilo, Jacson. Bozza, Fábio (Org). Estudos críticos sobre o sistema penal: homenagem ao Professor Doutor Juarez Cirino dos Santos por seu $70^{\circ}$ aniversário. Curitiba: LedZé, 2012. 
MARONNA, Cristiano Ávila. Nova lei de drogas: retrocesso travestido de avanço. Boletim IBCCRIM. São Paulo, v.14, n. 167, Outubro de 2006.

MELLO, Daniel. Tráfico de drogas é o crime que mais levou pessoas à prisão no Estado de São Paulo. Disponível em <http://justificando.com/2015/10/27/trafico-de-drogas-e-o-crime-que-maislevou-pessoas-a-prisao-no-estado-de-sao-paulo-

/?utm_content=bufferf79de\&utm_medium=social\&utm_source=twitter.com\&utm_campaign=buff er> Acesso em 02 de set. 2016.

PENTEADO FILHO, Nestor Sampaio. Manual Esquemático de Criminologia. $2^{\text {a }}$ edição. São Paulo: Saraiva, 2012.

VIANNA, Túlio; MACHADO, Felipe (coord.). Garantismo penal no Brasil: estudos em homenagem a Luigi Ferrajoli / Coordenadores Tulio Vianna; Felipe Machado. Belo Horizonte: Editora Fórum, 2013.

REDE BRASIL ATUAL. Descriminalização de drogas acabaria com 'justiça seletiva' feita pela polícia. Disponível em: <http://www.redebrasilatual.com.br/cidadania/2015/09/descriminalizacaode-drogas-pode-acabar-com-justica-seletiva-feita-pela-policia-5332.html>. Acesso em: 2 set. 2016.

ROCHA, Álvaro Filipe Oxley. Violência Simbólica: O Controle Social na Forma da Lei. Porto Alegre, EDIPUC, 2014

SOUZA. Fabio Luís Mariani de. Direito Fundamento à Defesa Criminal: Um olhar sobre a Defensoria Pública enquanto instrumento de acesso à justiça penal. Porto Alegre, 2010

UNIVERSO ON LINE - UOL. Brasil tem $4^{a}$ maior população carcerária do mundo, diz estudo do MJ. Disponível em: <http://noticias.uol.com.br/cotidiano/ultimas-noticias/2015/06/23/prisoesaumentam-e-brasil-tem-4-maior-populacao-carceraria-do-mundo.htm>. Acesso em: 2 set. 2016.

ZACKSESKI, Cristina; ANDRADE, Vera. A guerra contra o crime: permanência do autoritarismo na política criminal latino-americana. Verso e Reverso do controle penal. Homenagem a Alessandro Baratta. Vol. 2. Florianópolis: Fundação Boiteux, 2002, p. 123-131.

ZALUAR, Alba. Integração Perversa: pobreza e tráfico de Drogas. Rio de Janeiro: FGV, 2004.

ZAFFARONI, Eugenio Raúl; PIERANGELI, José Henrique. Manual de Direito Penal Brasileiro V.1. 7. ed. rev. São Paulo: Revista dos Tribunais, 2008

ZAFFARONI, Eugenio Raúl. El Enemigo en el Derecho Penal. Madrid: Dyckinson, 2006. 